\title{
Accuracy and Efficiency of Symmetrized Implicit Midpoint Rule for Solving the Water Tank System Problems
}

\author{
M. F. Zairul Fuaad ${ }^{1}$, N. Razali ${ }^{1,2, *}$, H. Hishamuddin ${ }^{1}$, A. Jedi ${ }^{1}$ \\ ${ }^{1}$ Department of Mechanical and Manufacturing Engineering, Faculty of Engineering \& Built Environment, \\ Universiti Kebangsaan Malaysia, Malaysia \\ ${ }^{2}$ Department of Engineering Education, Faculty of Engineering \& Built Environment, Universiti Kebangsaan Malaysia, Malaysia
}

Received August 2, 2021; Revised November 25, 2021; Accepted December 13, 2021

\section{Cite This Paper in the following Citation Styles}

(a): [1] M. F. Zairul Fuaad, N. Razali, H. Hishamuddin, A. Jedi, "Accuracy and Efficiency of Symmetrized Implicit Midpoint Rule for Solving the Water Tank System Problems, "Mathematics and Statistics, Vol. 10, No. 1, pp. 1 - 14, 2022. DOI: $10.13189 / \mathrm{ms} .2022 .100101$.

(b): M. F. Zairul Fuaad, N. Razali, H. Hishamuddin, A. Jedi (2022). Accuracy and Efficiency of Symmetrized Implicit Midpoint Rule for Solving the Water Tank System Problems. Mathematics and Statistics, 10(1), 1 - 14. DOI: 10.13189/ms.2022.100101.

Copyright $\odot 2022$ by authors, all rights reserved. Authors agree that this article remains permanently open access under the terms of the Creative Commons Attribution License 4.0 International License

\begin{abstract}
The accuracy and efficiency of water tank system problems can be determined by comparing the Symmetrized Implicit Midpoint Rule (IMR) with the IMR. Static and dynamic analyses are part of a mathematical model that uses energy conservation to generate a nonlinear Ordinary Differential Equation. Static analysis provides optimal working points, while dynamic analysis outputs an overview of the system behaviour. The procedure mentioned is tested on two water tank designs, namely, cylindrical and rectangular tanks with two different parameters. The Symmetrized IMR is used in this study. Results show that the two-step active Symmetrized IMR applied on the proposed mathematical model is precise and efficient and can be used for the design of appropriate controls. The cylindrical water tank model takes the fastest time in emptying the water tank. The approach of the various water tank models shows an increase in accuracy and efficiency in the range of parameters used for practical model applications. The results of the numerical method show that the two-step Symmetrized IMR provides more precise stability, accuracy and efficiency for the fixed step size measurements compared with other numerical methods.
\end{abstract}

Keywords Water Tank, Ordinary Differences Equation, Symmetrization Implicit Midpoint Rule, Accuracy, Efficiency

\section{Introduction}

A modelling system is a representation of the actual form modelled to illustrate the construction of relationships and elements of feature dependence and how the system works. Modelling is useful for the development of science, including creating systems that yet exist [1]. Models are a small representation of a nonlinear original system, with the expectation that the results of the experiments on this model are valid or comparable to those in the actual system. Accordingly, predictions for models are needed because actual experiments are risky and costly [2]. The mathematical model of the water tank system is described by the first nonlinear Ordinary Differential Equation (ODE) [3]. The model simulation consists of static and dynamic analyses.

Static analysis of imperative programs must be conducted to approximate their behaviour, for instance, in terms of their steady environments [4]. The output of the static analysis can be an optimal operating point or distance where the input variables diverge. [5]. Dynamic analysis observes the sequence of system behaviour after a change in step size (in this case a change in water height and time to empty the water tank). 
Numerical methods for the solution of the initial value problems in ordinary differential equations made enormous progress during the 20th century for the impetus that was given to the subject in the concluding years of the previous century by the seminal papers of Bashforth and Adams for linear multistep methods and Runge for Runge Kutta methods [6-7]. Numerical experiments will be conducted to investigate the accuracy and efficiency of this water tank system. The optimal tank design in a water drainage system can improve the accuracy and efficiency of water supply to the community [8]. Numerical methods are employed to solve a system of common differential equations formulated to estimate the approximate solutions because not all mathematical models have an accurate solution $[9,10]$.

The numerical method used in this system is called the Symmetrized Implicit Midpoint Rule (IMR). This method consists of one step and two step methods and both have active and passive modes, namely, One Step Active Method of Symmetry, One Step Passive Method of Symmetry, Two Step Active Method of Symmetry and Two Step of Passive Method (1AS, 1PS, 2AS, 2PS). The aforementioned method is designed to maintain symmetry (asymptotic $\mathrm{h}^{2}$-error expansion in step size $\mathrm{h}$ ) and dampen stiff issues. When combined with higher order approaches, the method also has the benefit of reducing order reduction [11]. The advantage of this numerical method is that it is new and has been used to program many applications (i.e. Prothero-Robinson in mathematical software, such as Matlab) [12]. This summary is divided into four main parts. The first part presents the introduction. The second part discusses the modelling procedure from the theoretical point of view of the actual model of the water tank. The third part illustrates the results and discussion of the experiments that have been conducted. The last part presents the conclusion.

All simulations are performed in Matlab version 2018a.

\section{Methodology}

Using the Symmetrized IMR, this study tries to determine which water tank has the best design for emptying the water tank. Based on this study, there are four types of water tanks, two of which have cylindrical water tanks and the other two are rectangular water tanks with capacities of 100 and 220 gal, respectively. The same pipe diameter of $25 \mathrm{~mm}$ has been used throughout the study. The parameters are compared in terms of speed of time with different tank diameters, heights, lengths and widths as in Table 1 and Table 2.

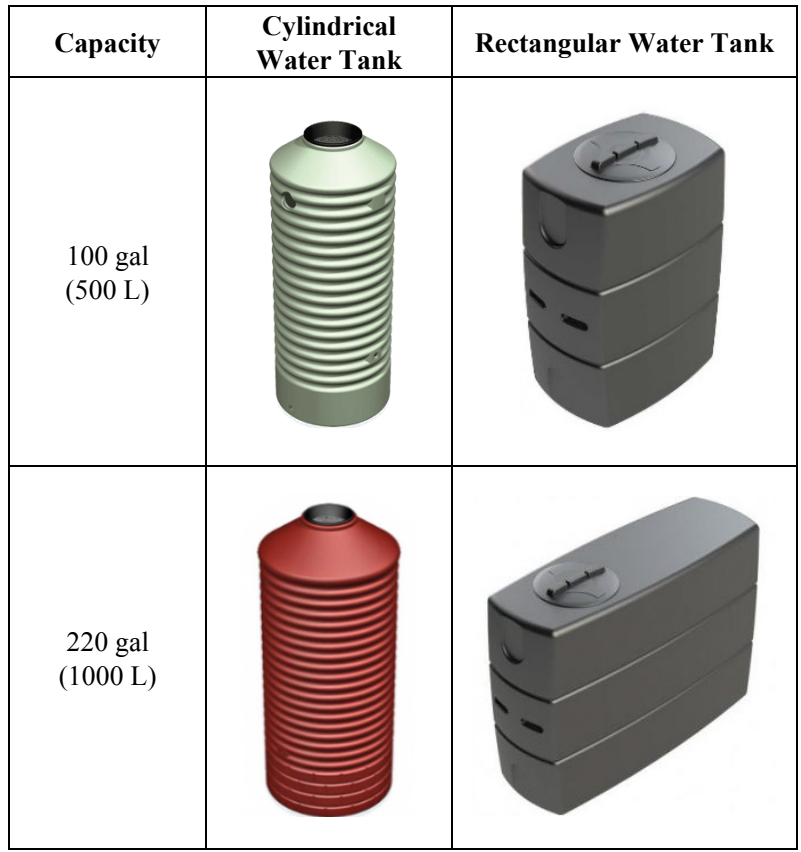

(Team Poly, 2018)

Table 1. Cylindrical water tank parameter set information

\begin{tabular}{|c|c|c|}
\hline Set Parameter & $\begin{array}{c}\text { Tank } \\
\text { Diameter, } \mathbf{m m}\end{array}$ & $\begin{array}{c}\text { Tank } \\
\text { Height, } \mathbf{~ m m}\end{array}$ \\
\hline First & 700 & 1775 \\
\hline Second & 900 & 2020 \\
\hline
\end{tabular}

Table 2. Rectangular water tank parameter set information

\begin{tabular}{|c|c|c|c|}
\hline $\begin{array}{c}\text { Set } \\
\text { Parameter }\end{array}$ & $\begin{array}{c}\text { Tank Width, } \\
\text { mm }\end{array}$ & $\begin{array}{c}\text { Tank Length, } \\
\text { mm }\end{array}$ & $\begin{array}{c}\text { Tank Height, } \\
\text { mm }\end{array}$ \\
\hline First & 650 & 870 & 800 \\
\hline Second & 670 & 1650 & 1200 \\
\hline
\end{tabular}

Applying the Bernoulli Principle to the flow of water in a water tank yields:

$$
\frac{v_{1}^{2}-v_{2}^{2}}{2 g}-\frac{p_{1}-p_{2}}{2 g}+\left(y_{1}-y_{2}\right)=0 .
$$

Given the small difference between $p_{1}$ and $p_{2}$, we estimate that $p_{1} \approx p_{2}$ and $v_{1} \ll v_{2}$ or $v_{1} \approx 0$.

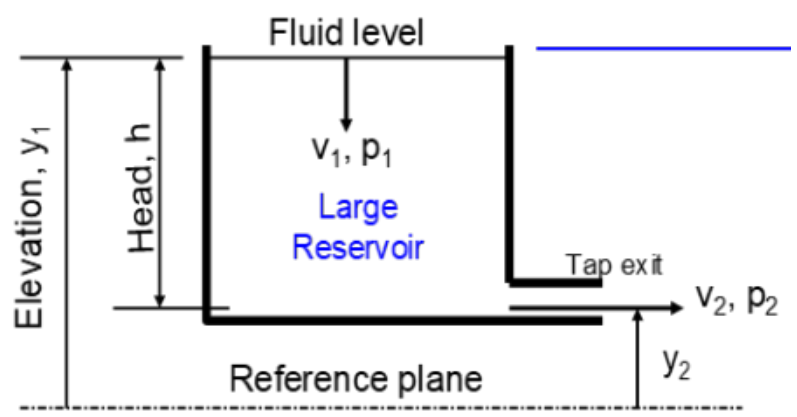


Equation (1) will be reduced to:

$$
-\frac{v_{2}^{2}}{2 g}+0+h=0,
$$

where $h=y_{1}-y_{2}$, and the velocity of the water exit is

$$
v=\sqrt{2 g h} \text {. }
$$

$\Delta \mathrm{t} \quad\left(\Delta \mathbf{V}_{\text {exit }}\right)$ for Cylindrical Water Tank and Rectangular Water tank, A v $(\mathrm{t}) \Delta \mathrm{t}$

$$
\text { Exit Velocity }=\left(\frac{\pi d^{2}}{4}\right) \sqrt{2 \mathrm{gh}(\mathrm{t}) \Delta \mathrm{t}}
$$

Let $\Delta h(t)=$ total decrease in the water level with increasing time by using Equation (3)

Then, the total LOSS of water in the tank is:

$$
\begin{aligned}
& \Delta \mathbf{V}_{\text {Cylindrical Water Tank }}=-\left(\frac{\pi D^{2}}{4}\right) \Delta \mathrm{h}(\mathrm{t}), \\
& \Delta \text { VRectangular Water Tank }=-l w \Delta \mathrm{h}(\mathrm{t}) .
\end{aligned}
$$

First Model: Cylindrical Water Tank
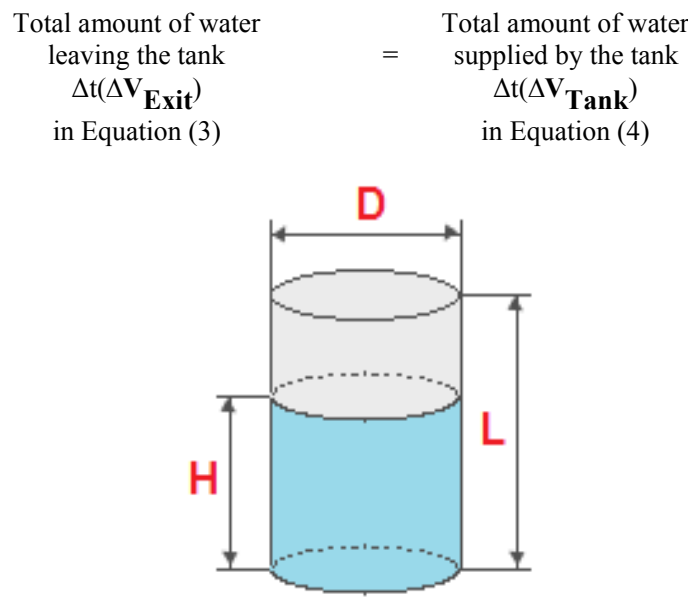

$$
\begin{gathered}
\left(\frac{\pi d^{2}}{4}\right) \sqrt{2 \mathrm{gh}(\mathrm{t}) \Delta \mathrm{t}}=-\left(\frac{\pi D^{2}}{4}\right) \Delta \mathrm{h}(\mathrm{t}) \\
\frac{\Delta \mathrm{h}(\mathrm{t})}{\Delta \mathrm{t}}=-\sqrt{2 \mathrm{~g}}\left(\frac{d^{2}}{D^{2}}\right) \sqrt{\mathrm{h}(\mathrm{t})}
\end{gathered}
$$

Second Model: Water Tank

$\begin{array}{cc}\begin{array}{c}\text { Total amount of water } \\ \text { leaving the tank }\end{array} & \begin{array}{c}\text { Total amount of water } \\ \text { supplied by the tank } \\ \Delta \mathrm{t}\left(\Delta \mathbf{V}_{\text {Exit }}\right)\end{array} \\ \Delta \mathrm{t}\left(\Delta \mathbf{V}_{\text {Tank }}\right) \\ \text { in Equation (3) } & \text { in Equation (5) }\end{array}$

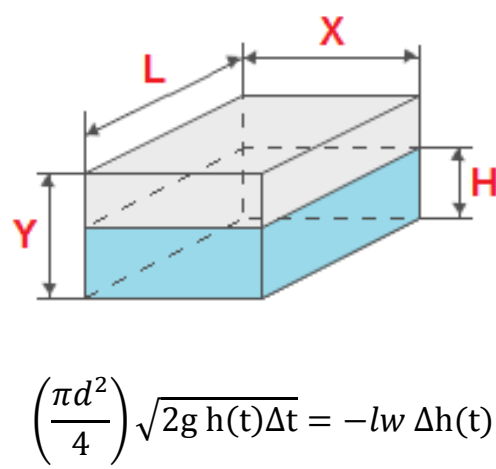

$$
\frac{\Delta \mathrm{h}(\mathrm{t})}{\Delta \mathrm{t}}=-\sqrt{2 \mathrm{~g}}\left(\frac{\pi d^{2}}{4 l w}\right) \sqrt{\mathrm{h}(\mathrm{t})}
$$

Table 3. Butcher Tableu for 1-step and 2-step symmetric method for IMR

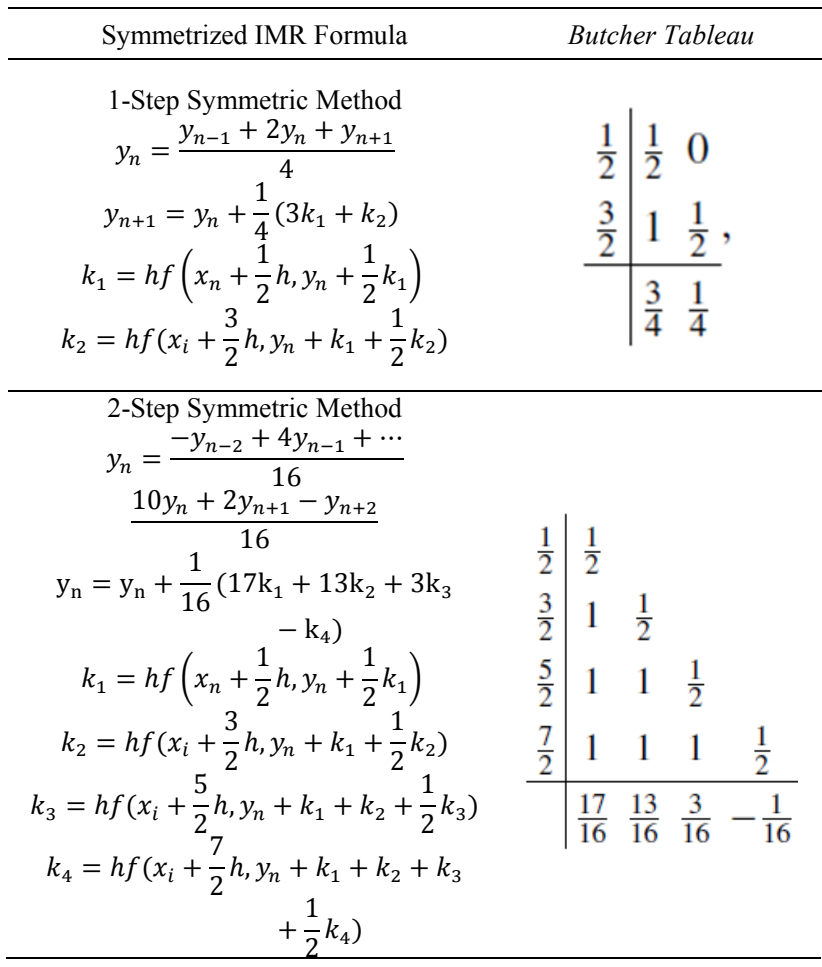

The advantage of the two-step symmetrization is that the method has the order two behaviour when it is applied in every step (active mode) compared with the order one behaviour of the one-step symmetrization. Table 3 shows the Butcher tableau for one-step and two-step symmetrizer of IMR.

We can apply the symmetrization process in either passive or active application. In the passive application, we run many steps with the symmetric method, store the update and internal stage values at each step and apply symmetrization whenever required.

The symmetrized value is used to propagate the numerical solution each time it is computed in the active mode. Symmetrization can be done at every step, every two steps, or a combination of these stages. Table 3 shows the Butcher tableaus for the one-step and two-step symmetrizers.

Table 4. Stability region for 1-step and 2-step symmetric method for IMR

\begin{tabular}{c}
\hline Stability Region Formula \\
Symmetrized IMR \\
1-Step Symmetric Method \\
$\tilde{R}(z)=\frac{1}{\left(1-\frac{1}{2} z\right)^{2}}$ \\
2-Step Symmetric Method \\
$\tilde{R}(z)=\frac{1-\frac{1}{2} z^{2}}{\left(1-\frac{1}{2} z\right)^{4}}$ \\
\hline
\end{tabular}


In this scenario, the method's $\mathrm{S}$ stability region is made up of all points in the complex plane. In the outer region, the colourless zone depicts values in a complex plane where the method is totally stable [13]. In the stability of the Symmetric Method, we can see the behaviour of the active mode in the first sequence and the passive mode in the second sequence by substituting the value of $\mathrm{z}$ to $h \lambda$. The global error maintains two step order behaviour because an equivalent one step order method is applied. Table 4 shows the formula for stability region.

\section{Results and Discussion}

\section{Time to Empty the Cylindrical Water Tank}

A water tank design is optimum when the system can supply the amount of water needed with sufficient pressure. The short time it takes to empty the tank demonstrates that the system has sufficient pressure to discharge the water [14]. The changes that occur in these two kinds of tank with two different sets of parameters can be explained using the energy distribution during the evacuation of these water tanks.

To find the time to empty the water tank, the graph below compares the four techniques in the Symmetrized IMR with the exact solution. The table above contains detailed information for each time and water level height for each graph. The step size for this approach is fixed at $25 \mathrm{~s}$. Figure 1 and Figure 2 show cylindrical water tanks with capacities of 100 and 220 gal of water that take 450 and $1400 \mathrm{~s}$ to empty, respectively. Meanwhile, Figure 3 and Figure 4 show rectangular water tanks with capacities of 100 and 220 gal of water, that take 1400 and $900 \mathrm{~s}$ to empty, respectively.

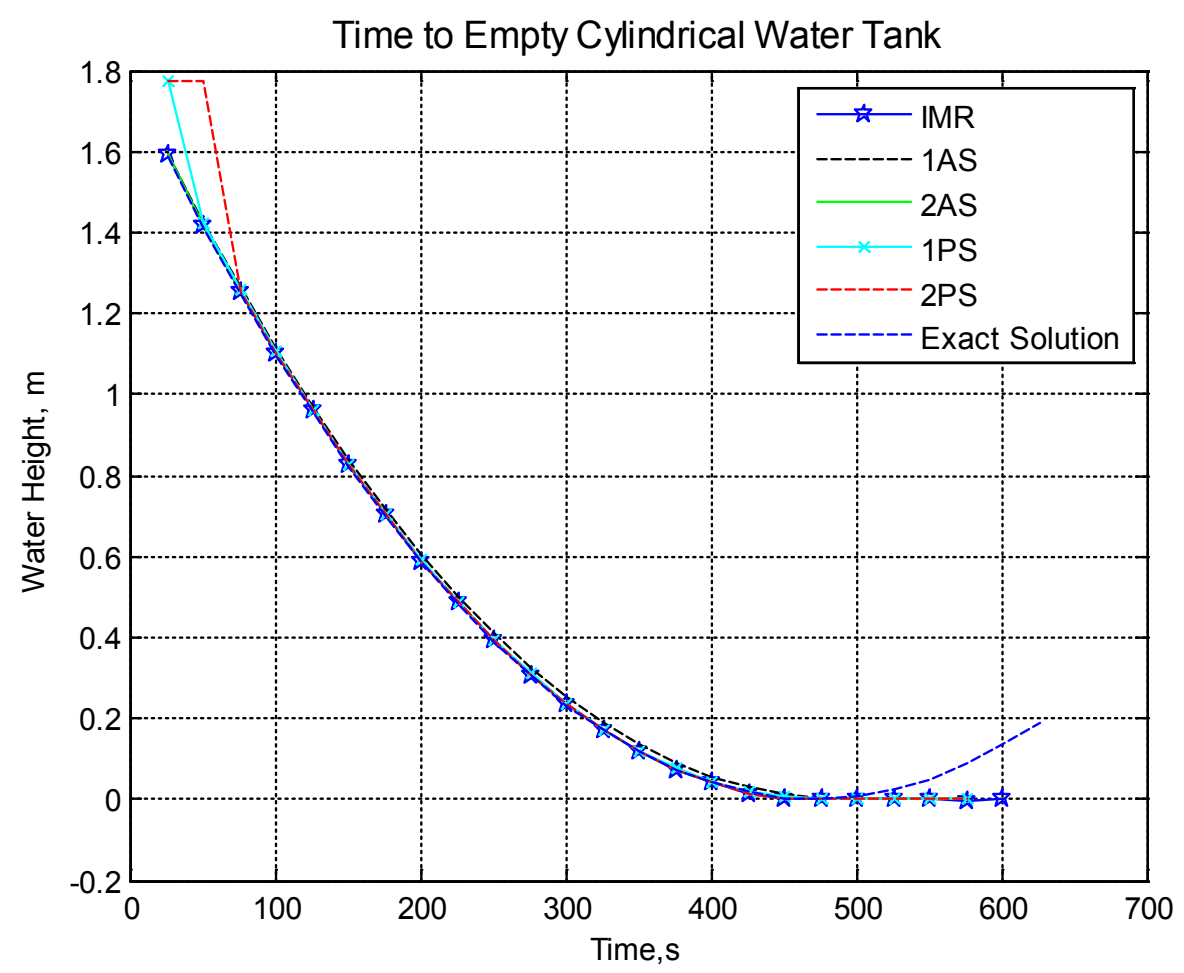

Figure 1. First Parameter for the $100 \mathrm{Gal}$ of Water 
Time to Empty Cylindrical Water Tank

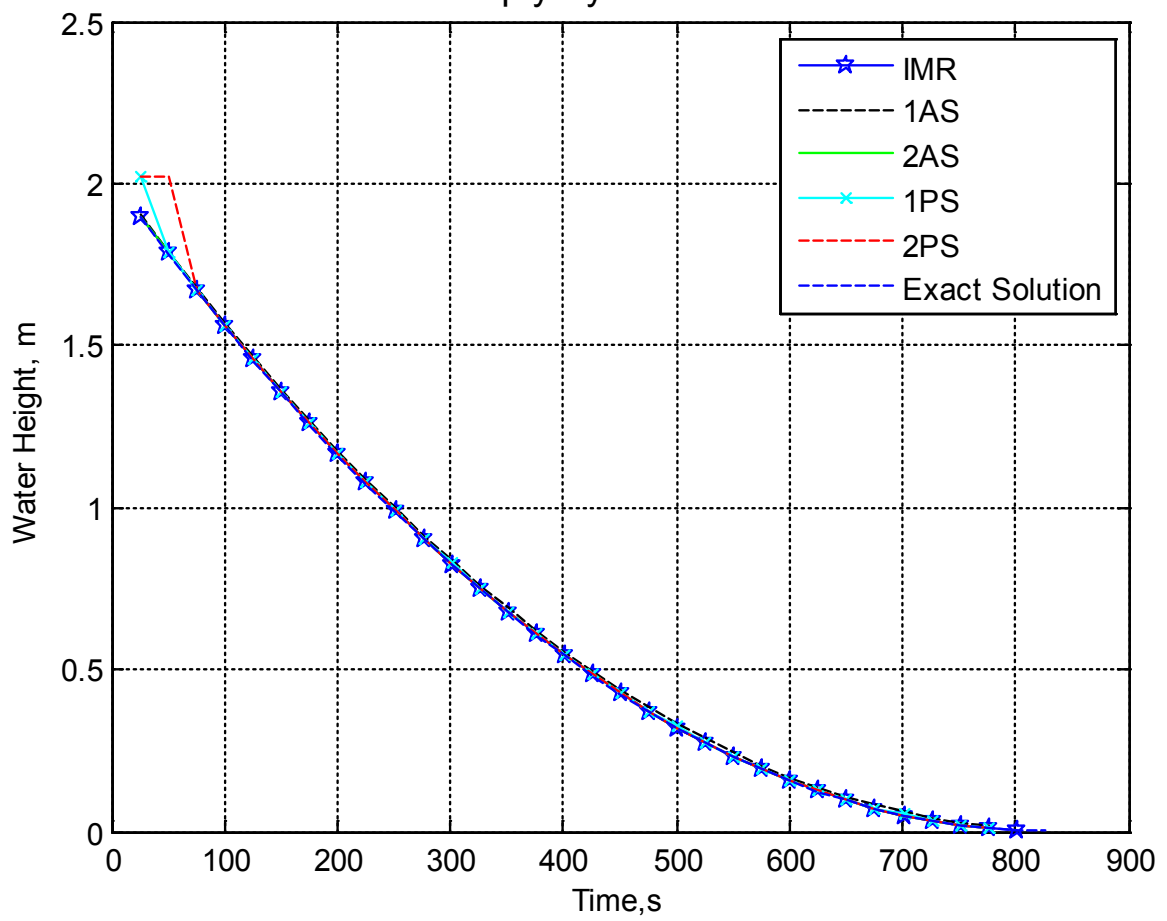

Figure 2. Second Parameter for the $220 \mathrm{Gal}$ of Water Time to Empty the Rectangular Water Tank

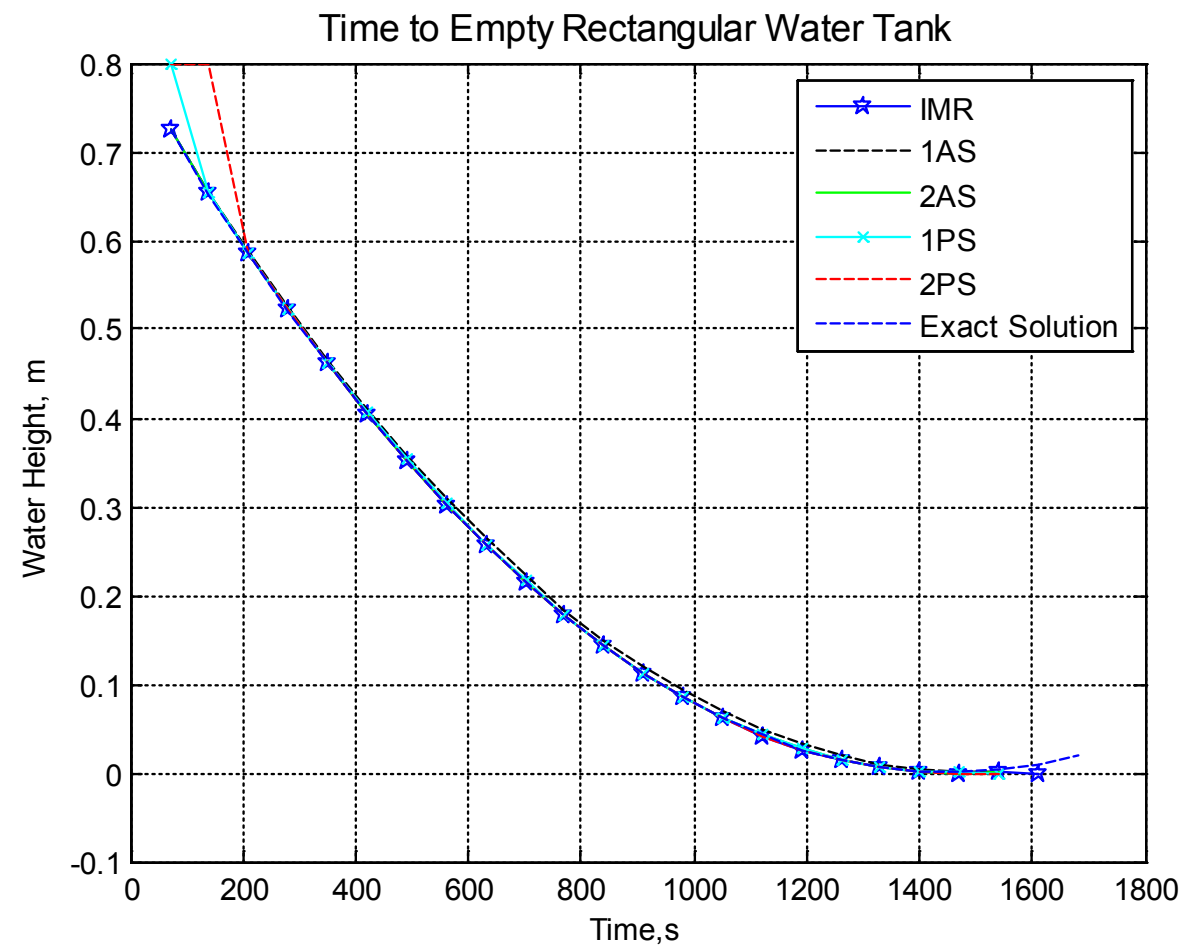

Figure 3. First Parameter for the $100 \mathrm{Gal}$ of Water 


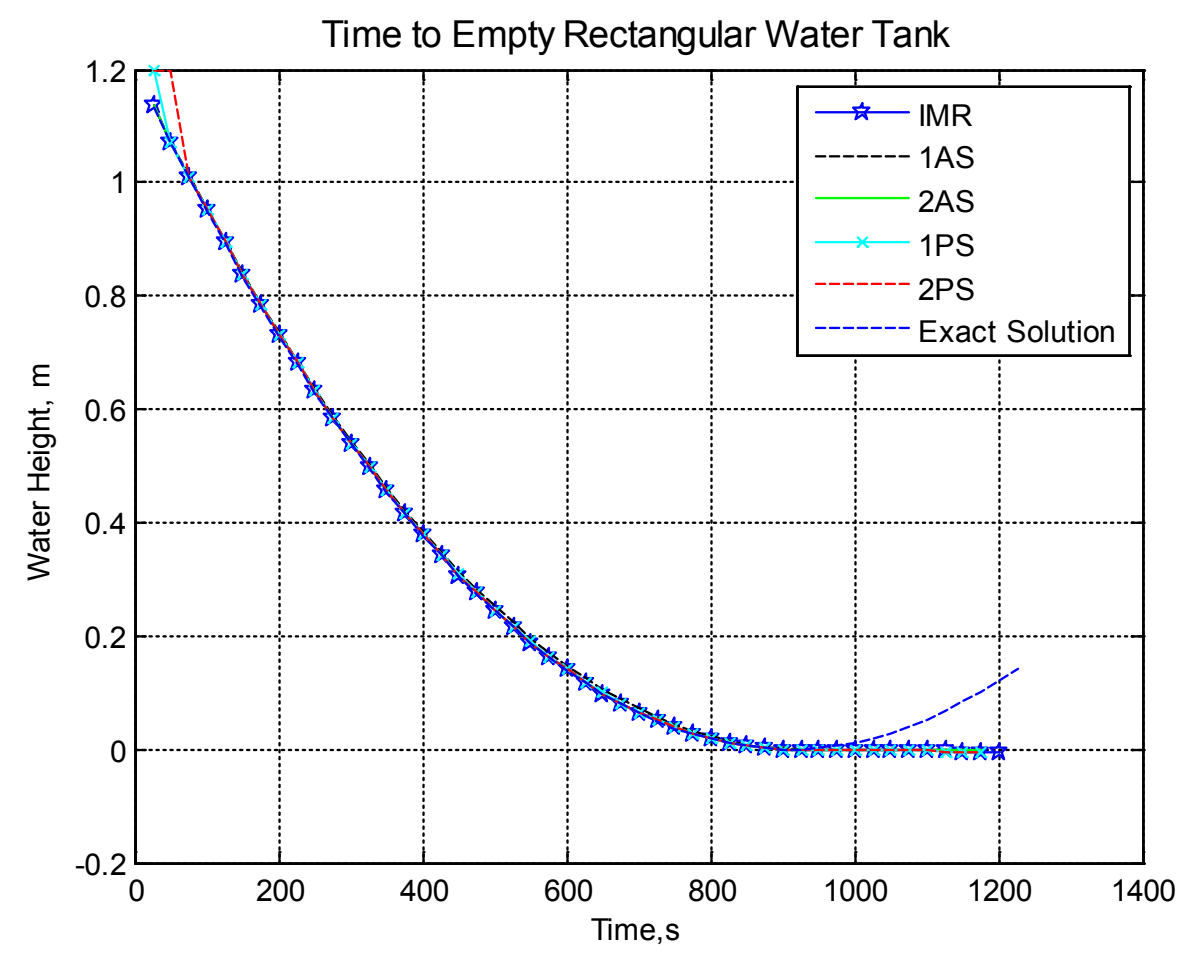

Figure 4. Second Parameter for the $220 \mathrm{Gal}$ of Water

\section{ACCURACY OF THE SYMMETRISED IMR}

The Symmetrised IMR analytical algorithm considers the numerical solution as an exact solution of a problem close to the original problem to evaluate the accuracy of a numerical solution. This process distinguishes the Symmetrised IMR analysis from the direct error analysis, which calculates the correctness of numerical solution errors. In the direct error analysis, a large increase in the bounds of estimates is noted, which greatly exceeds the values of the numerical errors themselves in most cases [15].
Figure 5 to Figure 8 show the log of error of the active and passive symmetries of the Symmetrised IMR. In Symmetrised IMR, the 2PS method has the shortest time compared with other methods. The 2PS implicit method has high accuracy compared with other methods in just approximately 400 and $600 \mathrm{~s}$ for a cylindrical water tank and 1200 and $700 \mathrm{~s}$ for a rectangular water tank. Thereafter, this method has a relatively low accuracy compared with other methods. The 2AS method has accurate solution compared with the other methods. The longer the time passes, the higher the accuracy of this method. 


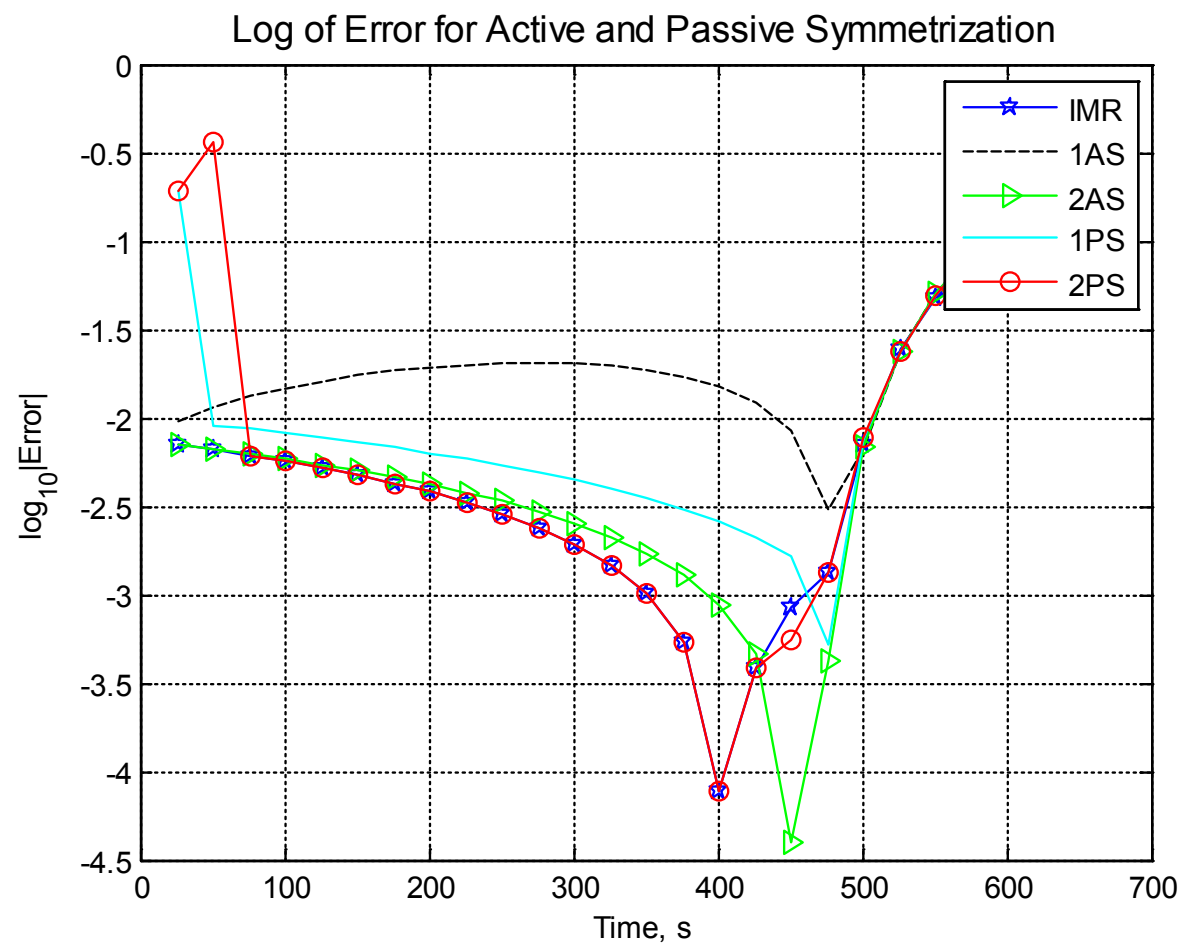

Figure 5. Log Error Graph for the 100 Gal Cylindrical Water Tank

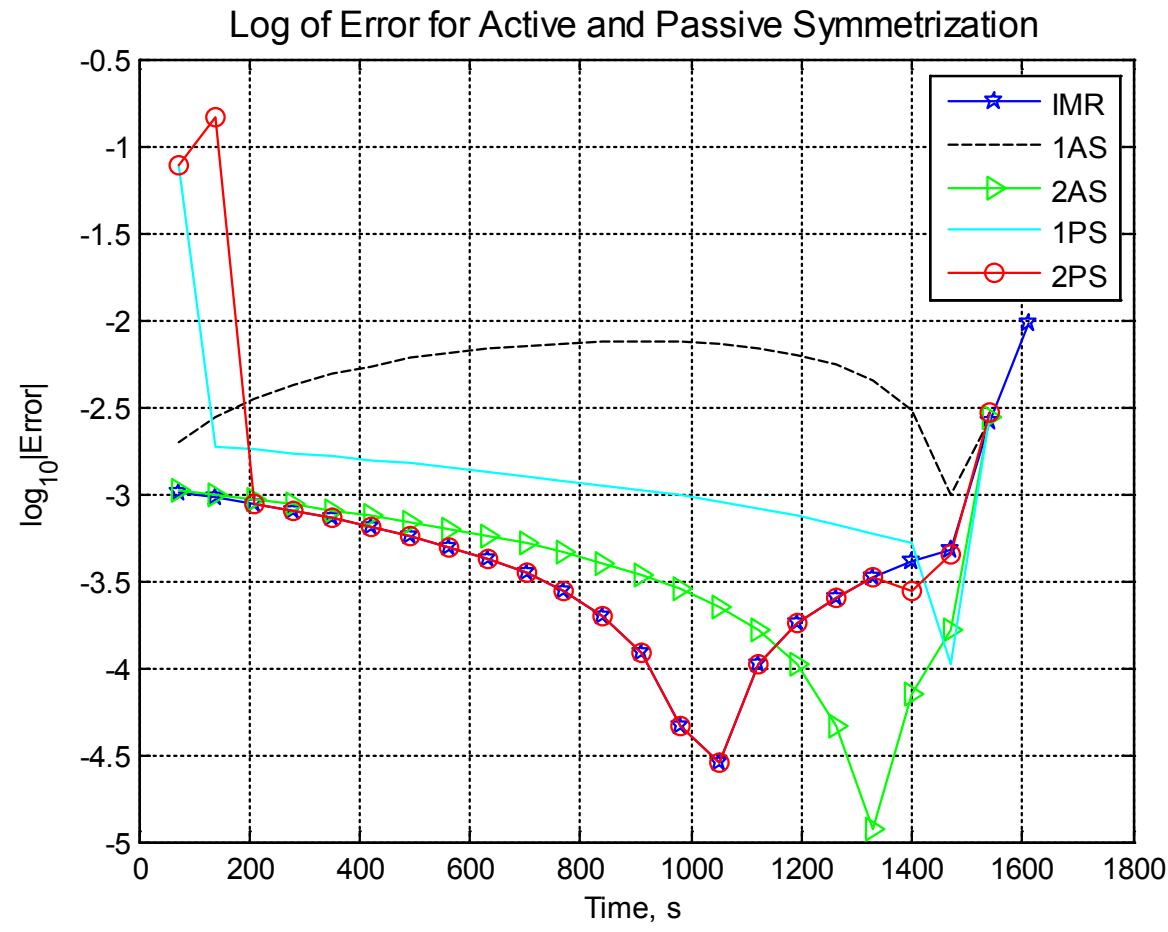

Figure 6. Log Error Graph for the $100 \mathrm{Gal}$ Rectangular Water Tank 


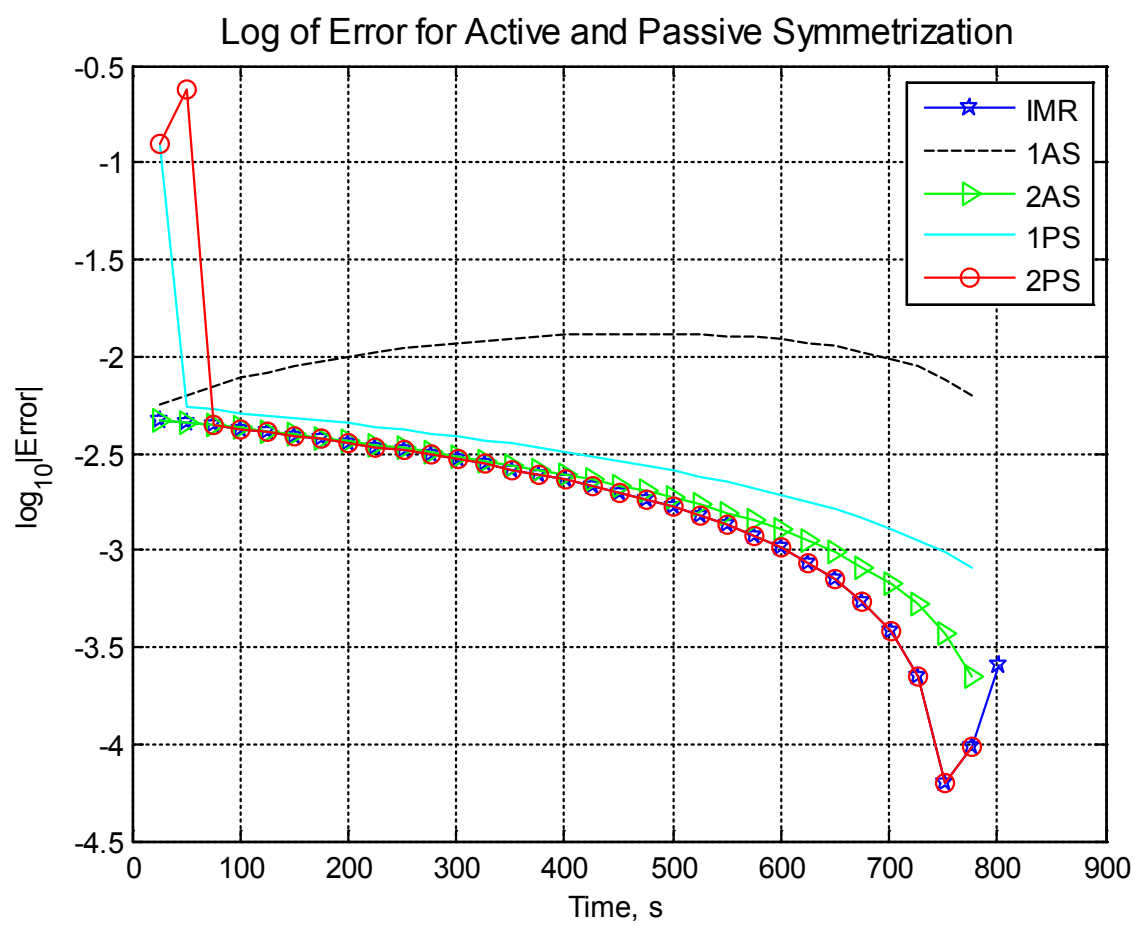

Figure 7. Log Error Graph for the 220 Gal Cylindrical Water Tank

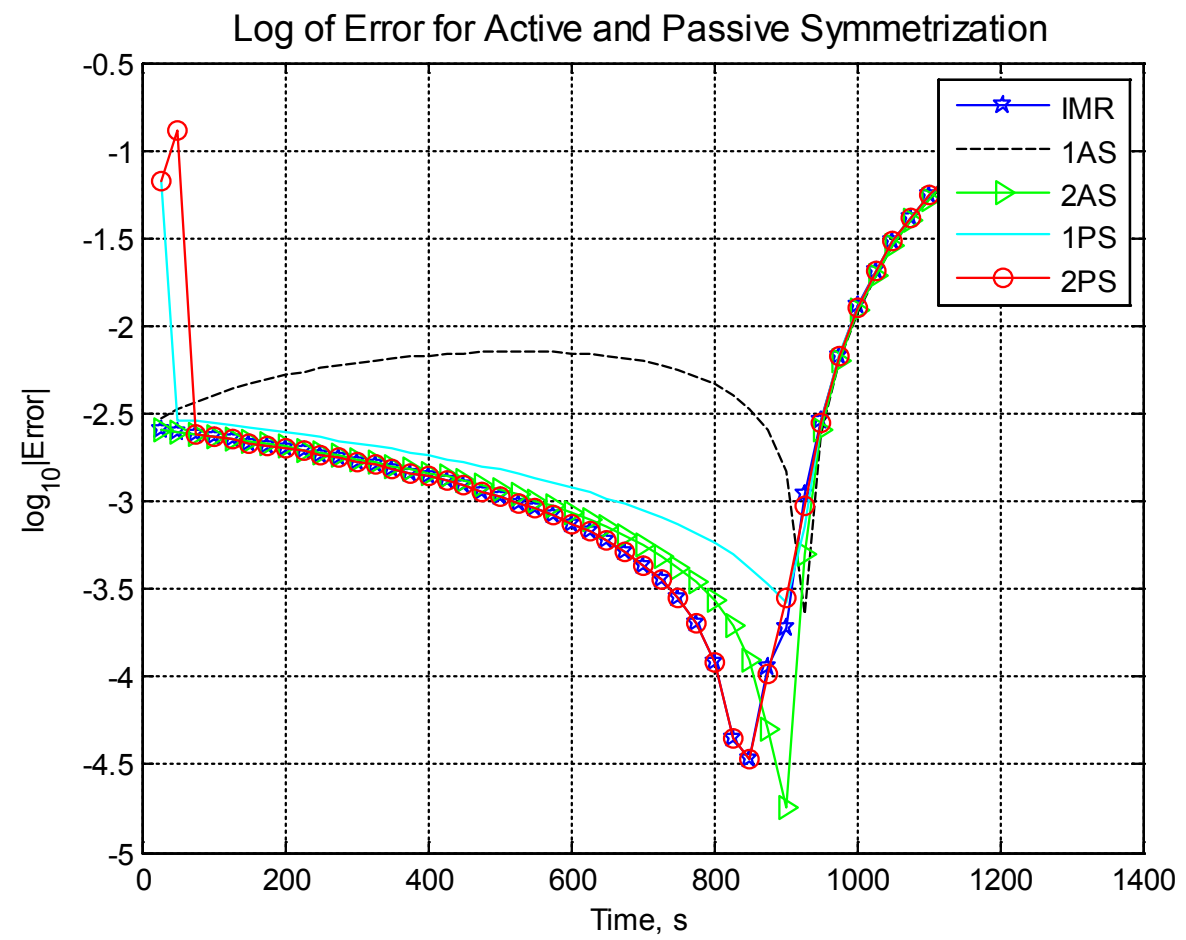

Figure 8. Log Error Graph for the $220 \mathrm{Gal}$ Rectangular Water Tank

\section{EFFICIENCY OF SYMMETRIZATION IMR}

The efficiency of each numerical method is observed in terms of the total CPU time required for the solution to a given limit of accuracy. This aspect depends directly on the total number of iterations and the CPU time per iteration. The latter is a reflection of the complexity of the numerical algorithm. In terms of the total CPU time, the efficiency of the stiffness Symmetrization IMR is 
comparable with that of the dynamic analysis algorithm [16].

Figure 9 to Figure 12 show the log of error diagram against the total CPU time to determine the most efficient method for the design of a suitable water tank. The method that has the highest efficiency is the one that approaches the water height at $0 \mathrm{~mm}$ in the shortest time. The results indicated that the 2PS had the highest efficiency in experimental emptying of the cylindrical and rectangular water tanks in the existing methods for the first and second parameters, followed by the 2AS, 1PS and 1AS methods in the Symmetrised IMR.

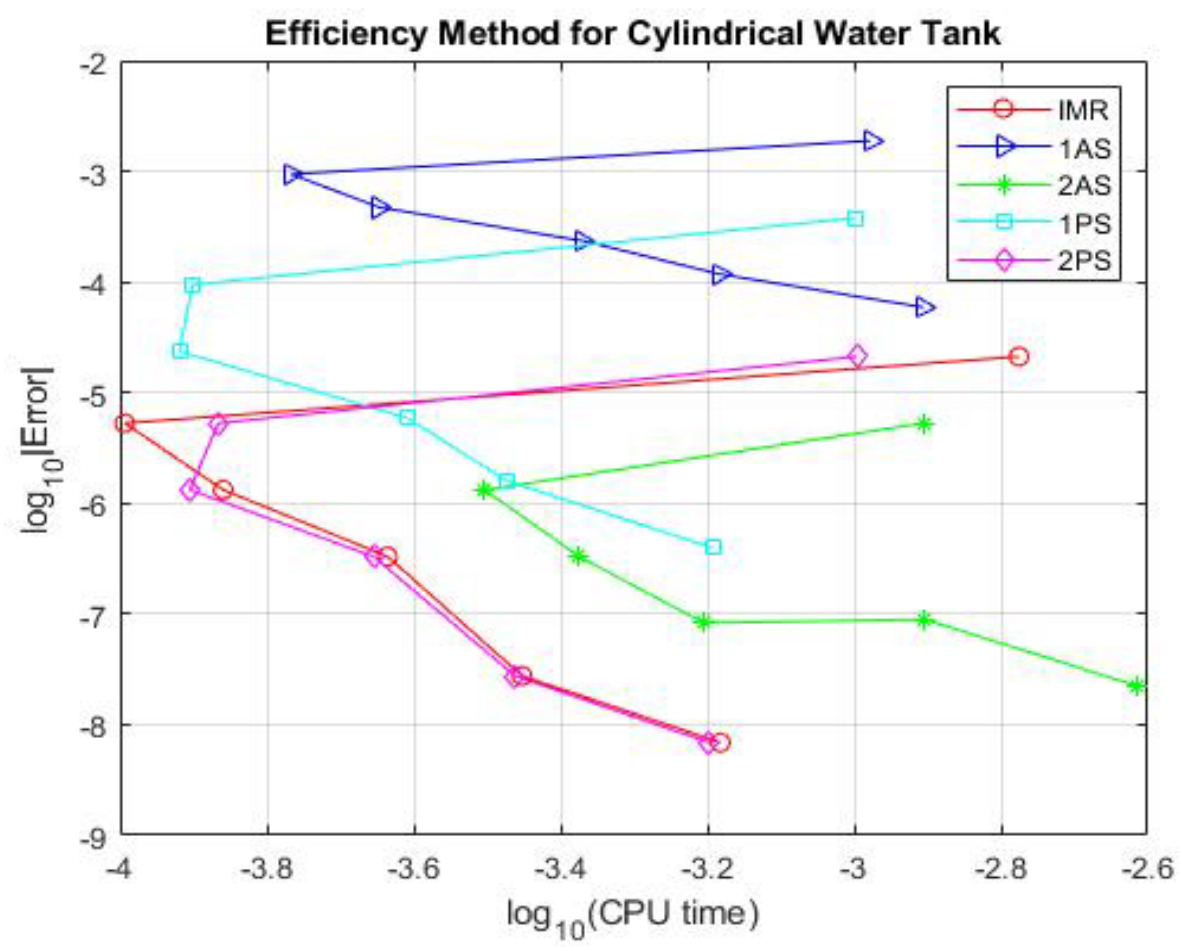

Figure 9. Log Error Graph for the $100 \mathrm{Gal}$ Cylindrical Water Tank

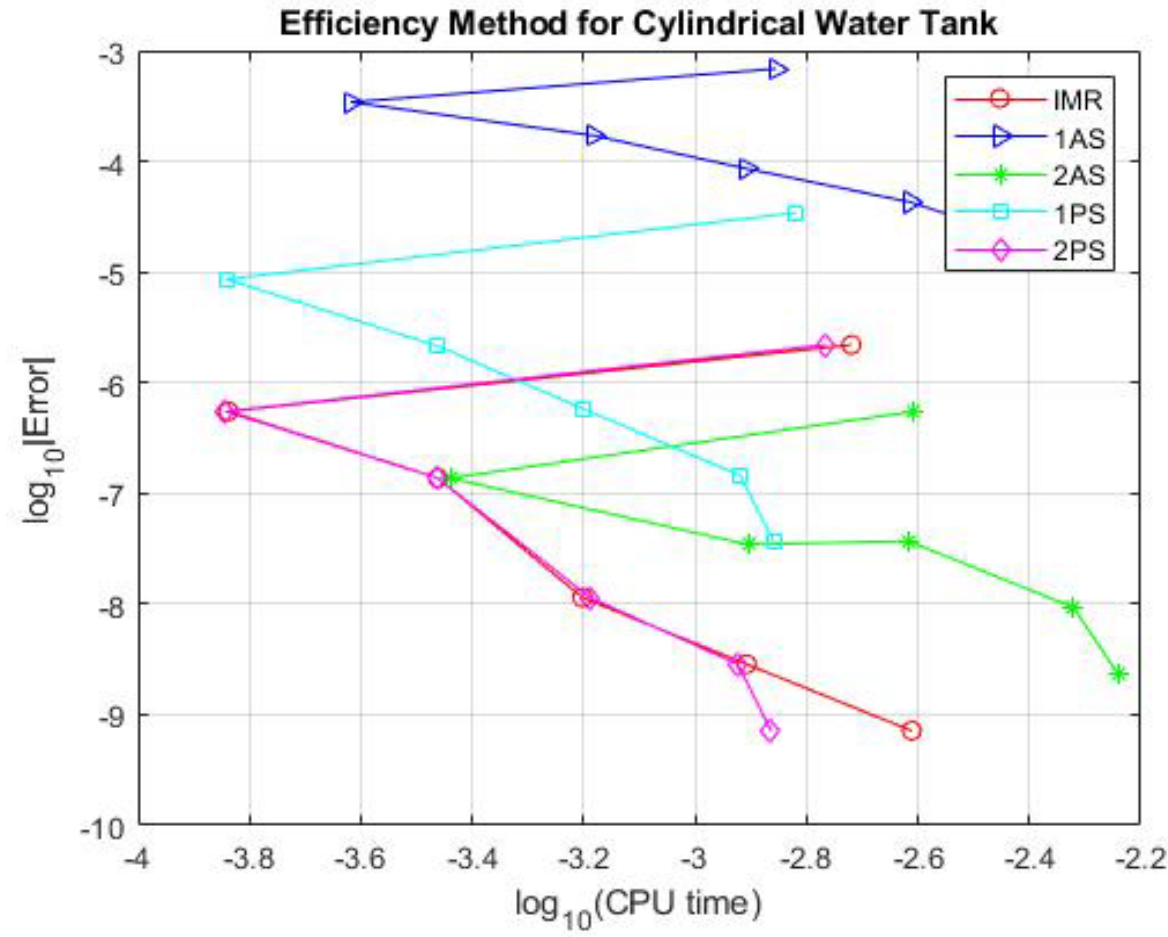

Figure 10. Log Error Graph for the $100 \mathrm{Gal}$ Rectangular Water Tank 


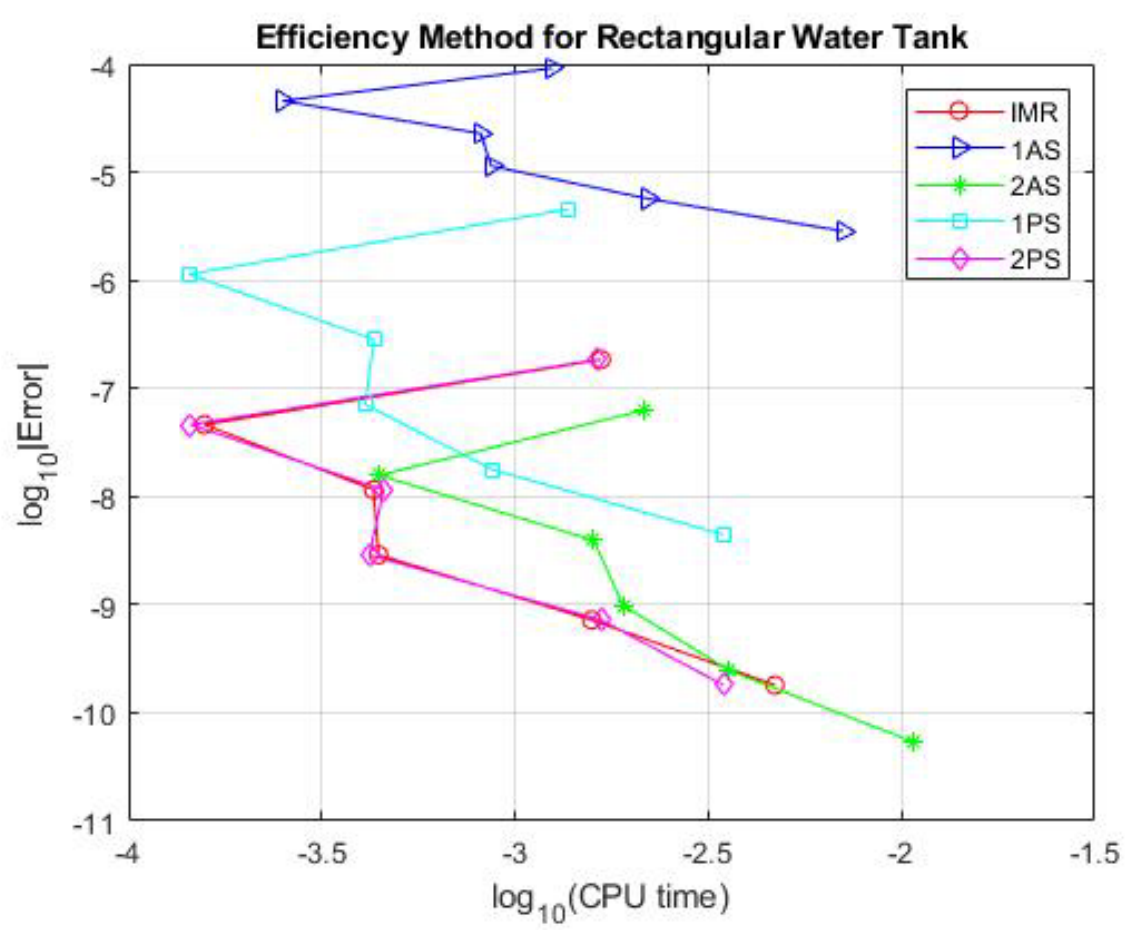

Figure 11. Log Error Graph for the 220 Gal Cylindrical Water Tank

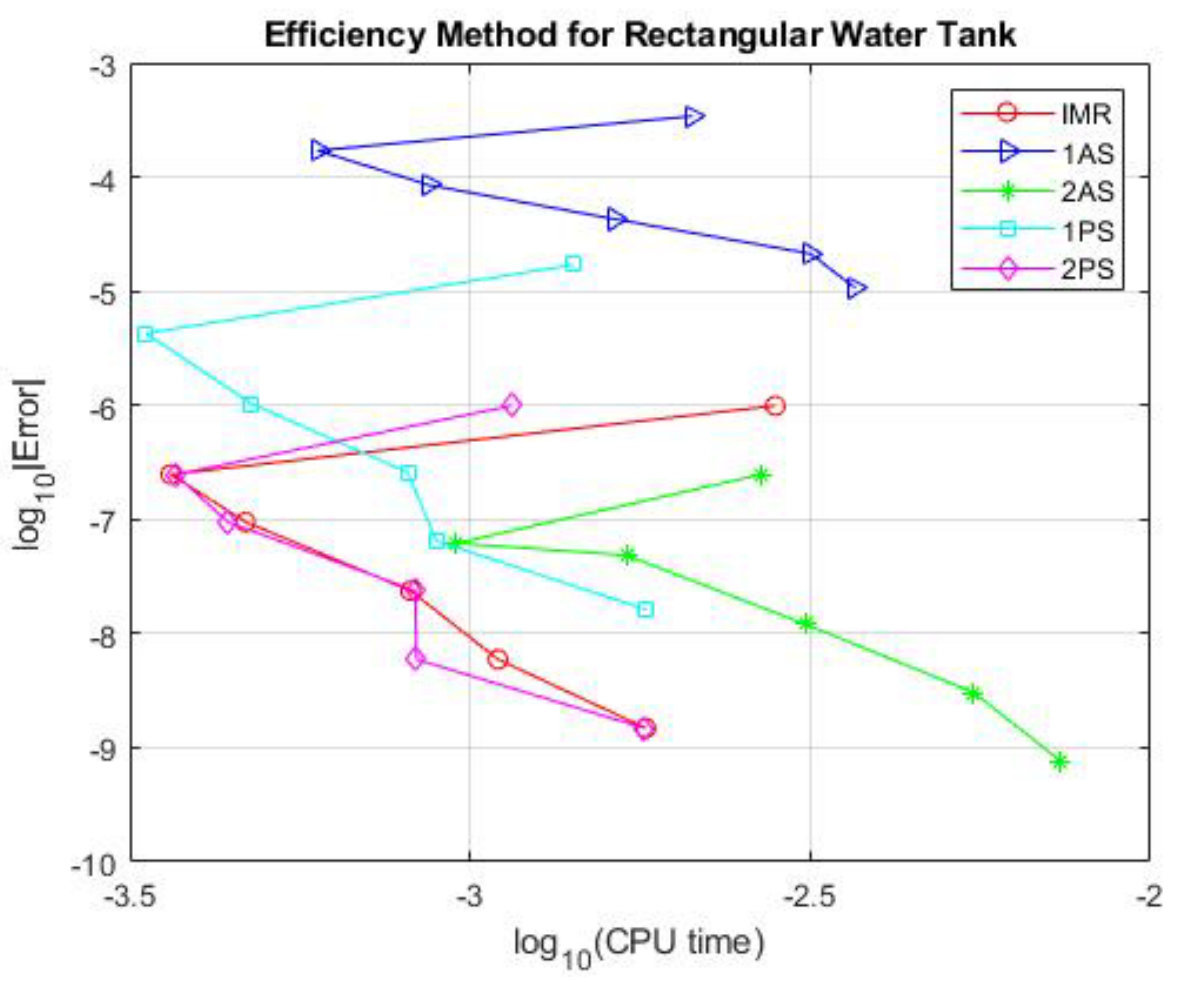

Figure 12. Log Error Graph for the 220 Gal Rectangular Water Tank

\section{ORDER BEHAVIOUR OF THE SYMMETRISED IMR}

In a numerical method's stability analysis, the focus is on the behaviour of the global error as $t$ after some errors have been added, rather than the source of the error. The behaviour of the global error is determined by the behaviour of the ODE solution. If a method's absolute stability is independent of $\mathrm{h}$, we get the following definition, which is similar to ODE's A-stability definition [17].

Figure 13 to Figure 16 show the Order Behaviour of the 
Symmetrised IMR on the parameters of a cylindrical water tank and a rectangular water tank. 1AS is the first sequence of the Symmetrized IMR because the gradient value is equal to one. 1PS, $2 \mathrm{AS}$ and $2 \mathrm{PS}$ belong to the two step of the Symmetrized IMR because they have a gradient value equal to two. Moreover, the 2AS located at the bottom of the graph illustrates that it is the most accurate method.

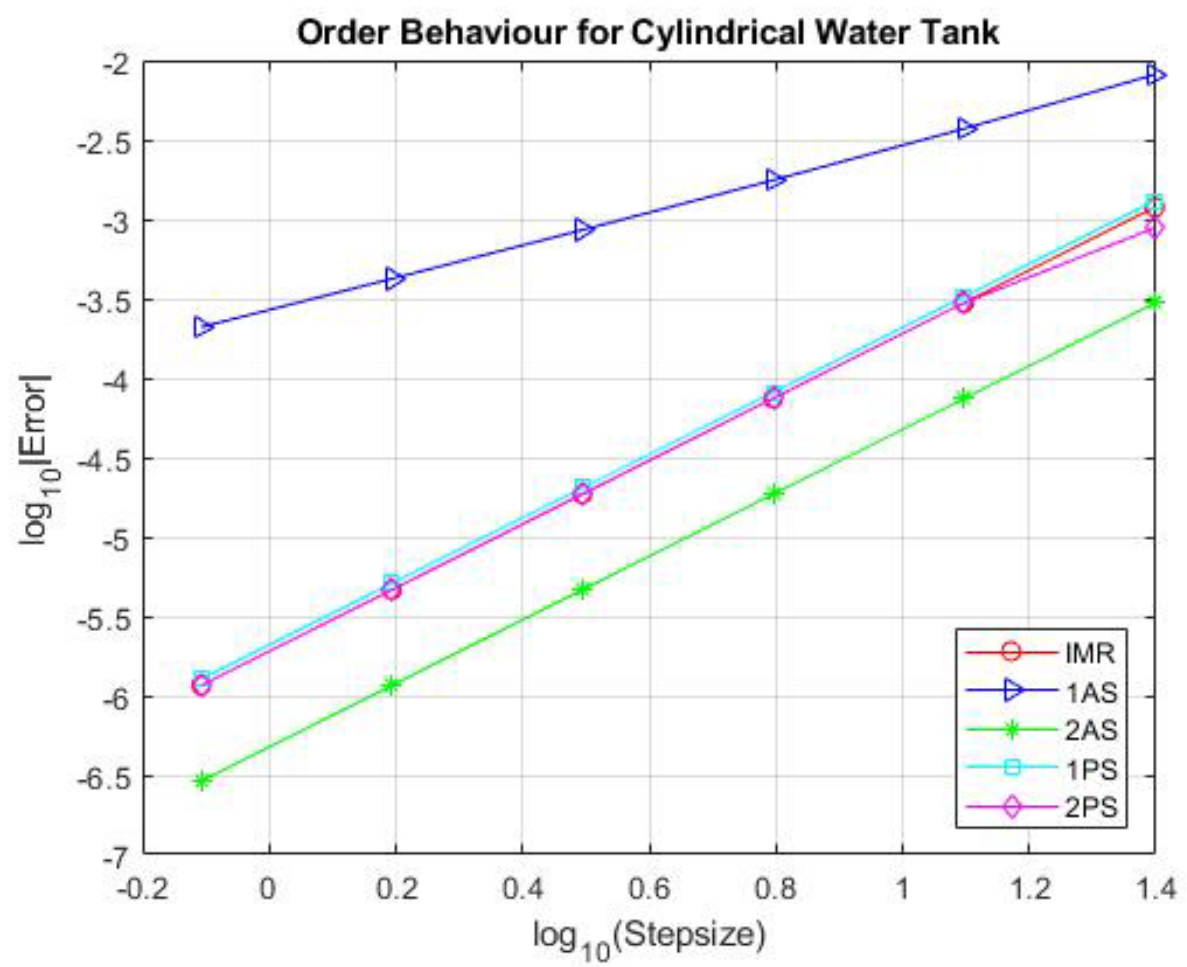

Figure 13. Order Behaviour of the 100 Gal Cylindrical Water Tank

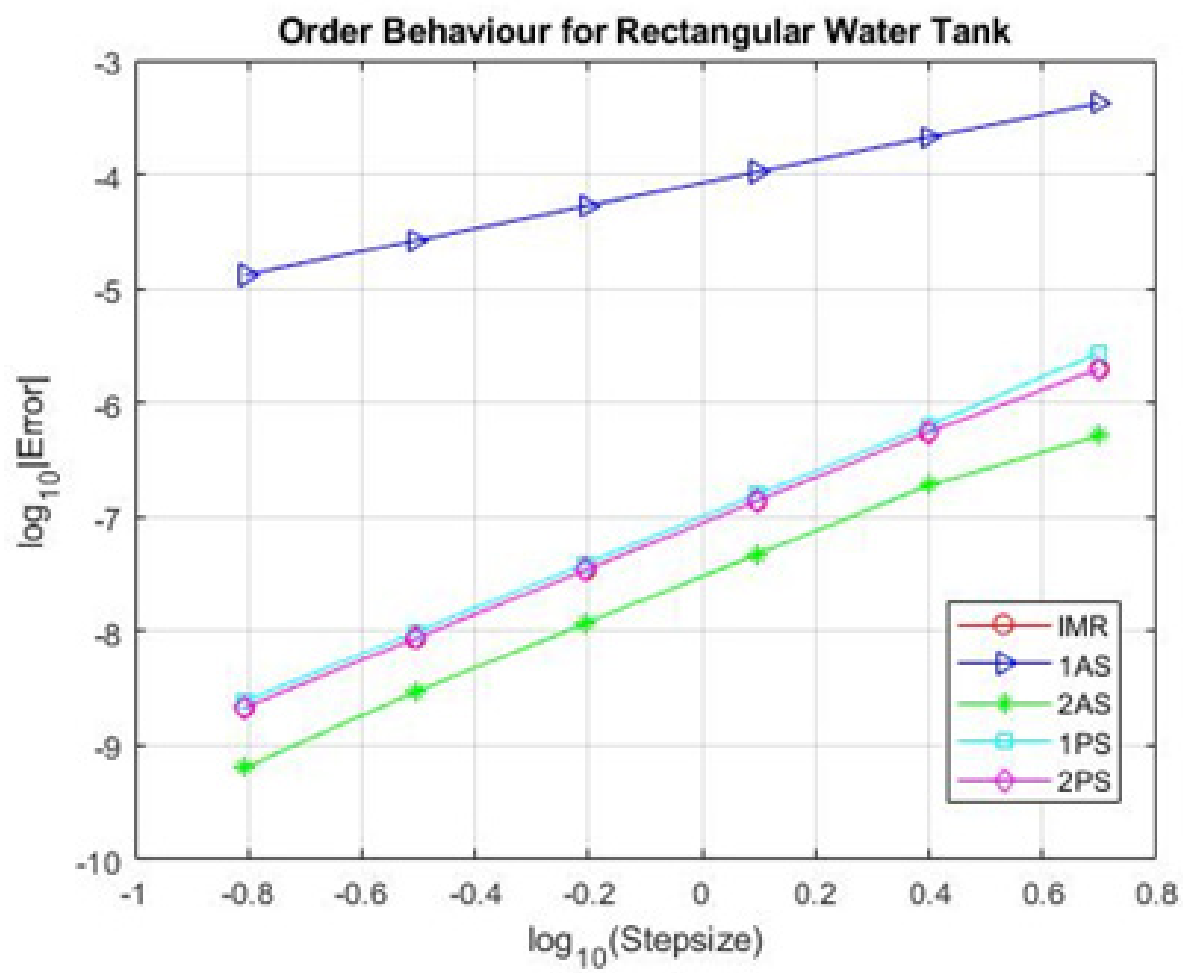

Figure 14. Order Behaviour of the $100 \mathrm{Gal}$ Rectangular Water Tank 


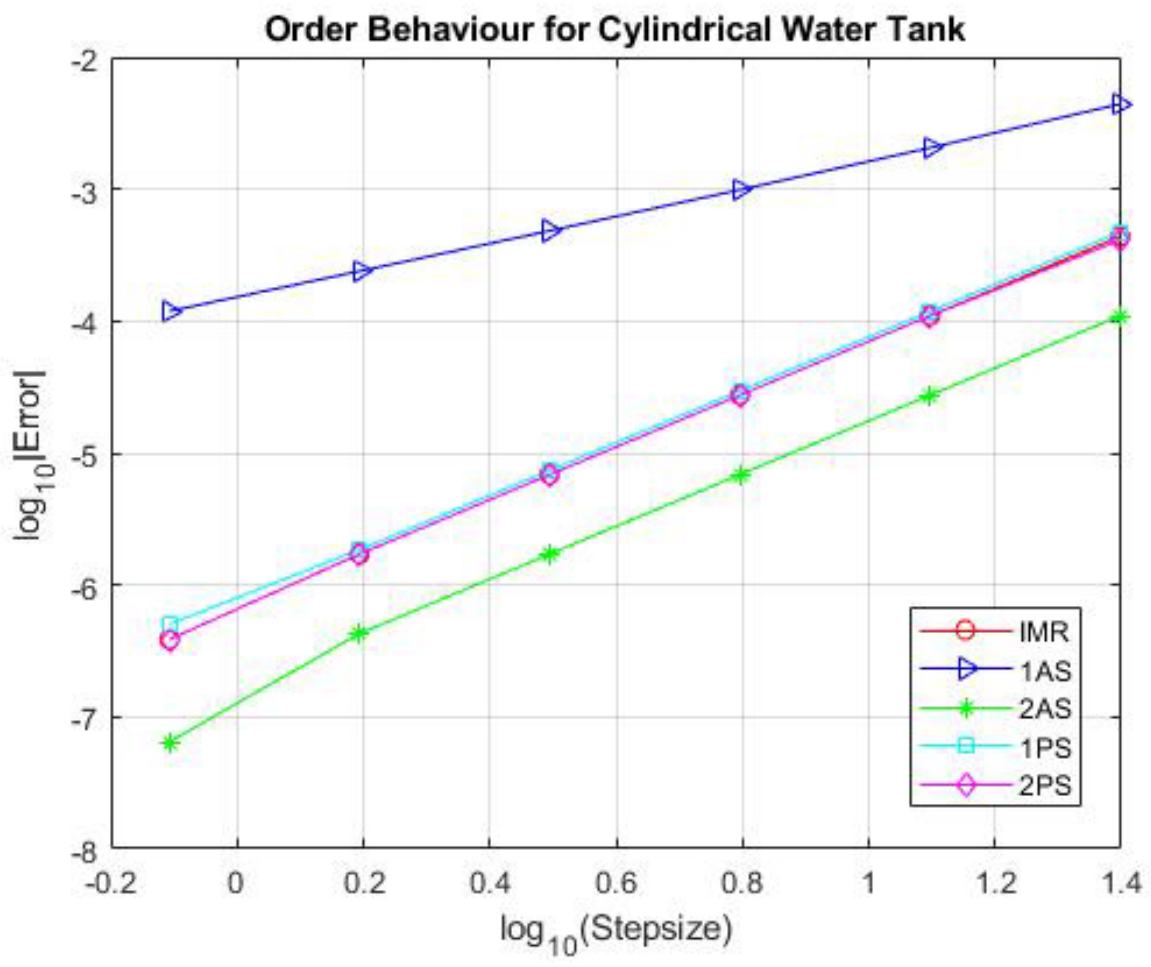

Figure 15. Order Behaviour of the $220 \mathrm{Gal}$ Cylindrical Water Tank

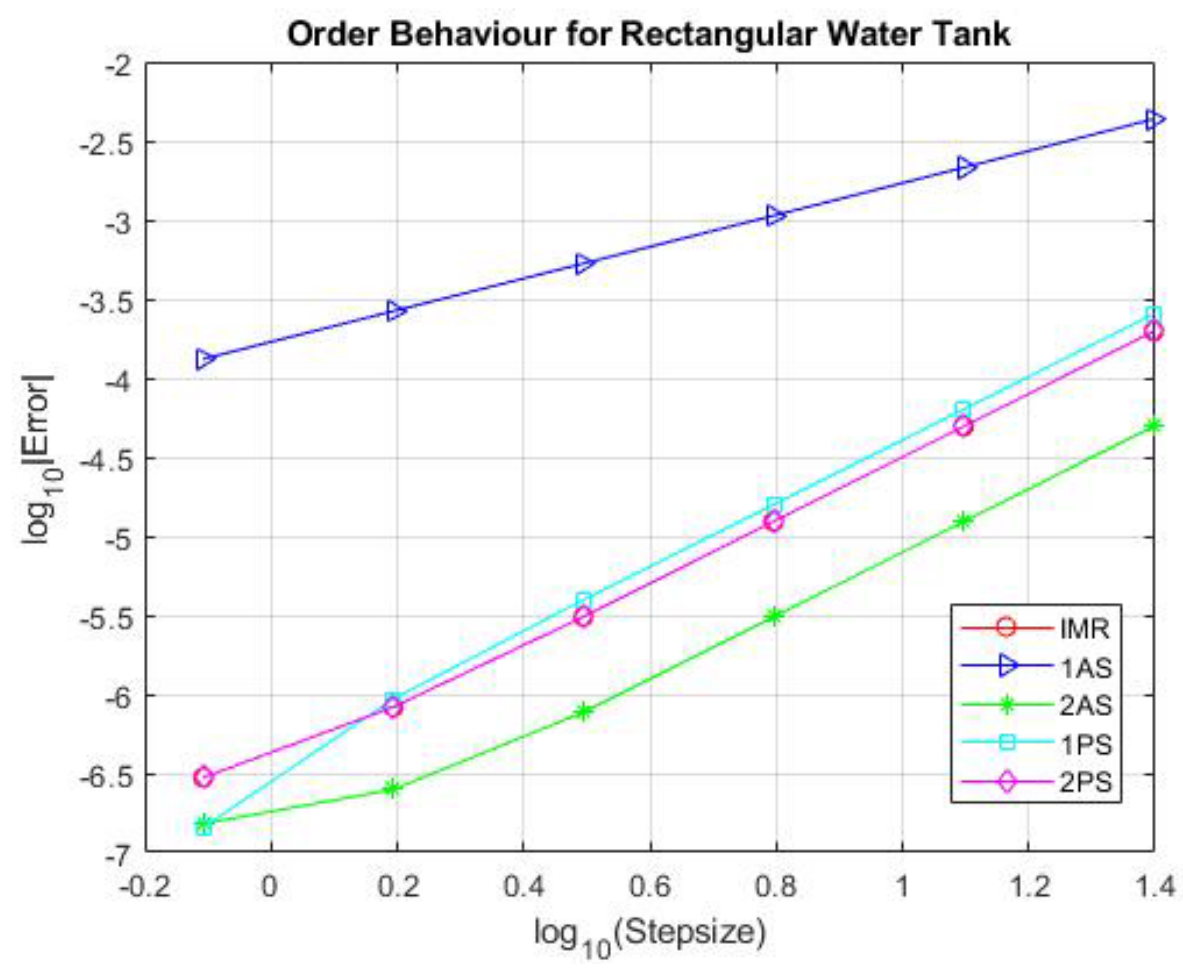

Figure 16. Order Behaviour of the $220 \mathrm{Gal}$ Rectangular Water Tank 


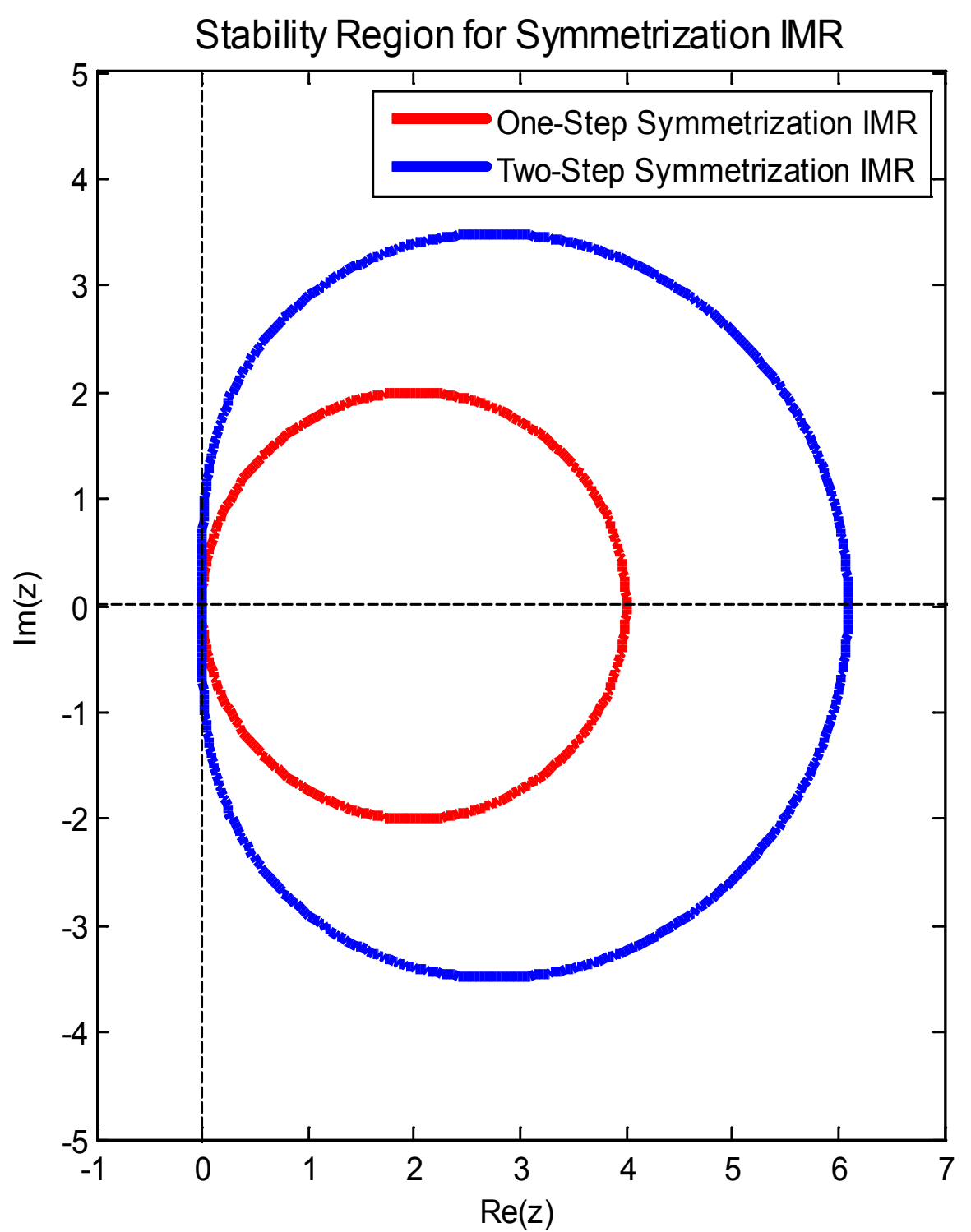

Figure 17. Stability Region of the Symmetrized IMR

In terms of the stability of the Symmetrised IMR for the parameters and rigid water tank models with $\lambda=-1$, all methods are in sequence two, except 1AS, which is one order. The cylindrical water tank model shows the Symmetrised IMR, 1PS and 2PS located on the same line. The colourless areas indicate values $\mathrm{h} \lambda$ in an implicit complex plane where the method is completely stable. The diagram in Figure 17 illustrates that the One-step Symmetrised IMR has a wide area of stability compared with the Two-step Symmetrised IMR because the outer area of the former is far larger than that of the latter.

\section{Conclusions}

This research aims to establish two mathematical models for the water tank and analyse its accuracy and efficiency by using the Symmetrized IMR. Moreover, this research was successful in achieving the objective that was set. One of the characteristics of an ideal water tank is that it must be able to supply water to all of the designated locations with the appropriate level of pressure and supply enough of water needed whenever the main water flow is not functioning. Based on the research result obtained, the first parameter set for the cylindrical water tank has the best time to empty the water tank, and its diameter is 700 $\mathrm{mm}$ with $1775 \mathrm{~mm}$ height. This model and parameter helped in emptying the water tank in 7 min according to the suitable tank that is used at home rather than the other models and parameter sets.

A super convergent order two behaviour is observed when the constant step size is $h=25$. The two-step symmetrization is shown to be more accurate and efficient for variable step sizes compared with one-step 
symmetrization. Some results show that the total number of steps taken are greater in the two-step than one-step symmetrization, showing that the former is more accurate than the latter. Based on the Symmetrized IMR, the two-step passive Symmetrization shows the lowest graph plot than the other three symmetrization methods.

\section{Acknowledgments}

The authors fully acknowledged University Kebangsaan Malaysia and Ministry of Higher Education under the grant FRGS/1/2020/TK0/UKM/02/29 for opportunity which makes this important research viable and effective.

\section{REFERENCES}

[1] Robinson, S., Arbez, G. \& Louis G. Birta et al., "Conceptual Modeling: Definition, Purpose and Benefits," Winter Simulation Conference (WSC). IEEE, 2015 (2012): 779790,2015

[2] R.W. McHaney., "Understanding Computer Simulation," 2009.

[3] Forbes, L. K. \& Hocking, G. C., "Flow Caused By A Point Sink In A Fluid Having A Free Surface (March 1989): 231-249," 1990.

[4] Goubault, E., Le Roux, S., Leconte, J., Liberti, L. \& Marinelli, F., "Static analysis by abstract interpretation: A mathematical programming approach," Electronic Notes in Theoretical Computer Science 267(1): 73-87, 2010. DOI: 10.1016/j.entcs.2010.09.007

[5] Vojtesek, J., Dostal, P., Maslan, M., Republic, C. \& Model., "Modelling and Simulation of Water Systems.Pdf 8(Cd)," 2014.

[6] Butcher, J. C., "Numerical methods for ordinary differential equations in the 20th century," Journal of Computational and Applied Mathematics 125(1-2): 1-29, 2000. DOI: 10.1016/S0377-0427(00)00455-6
[7] J. C. Butcher., "The Numerical Analysis of Ordinary Differential Equations," Runge-Kutta and General Linear Methods. Wiley, Chichester, New York, 1987.

[8] Rose J, D. K. \& S, A. A., "A Study of Overhead Water Tanks Subjected to Dynamic Loads," International Journal of Engineering Trends and Technology 28(7):344-348, 2015.

[9] J. R. Cash and A. H. Karp., "A variable order Runge-Kutta method for initial value problems with rapidly varying right-hand sides." ACMTransactions on Mathematical Software, 16:201-222, 1990.

[10] S. Al-Ahmad et al, "A Modification of Differential Transform Method for Solving Systems of Second Order Ordinary Differential Equations," Mathematics and Statistics, $\quad 8(4)$ : 464-47, 2020, DOI: $10.13189 / \mathrm{ms} .2020 .080414$.

[11] R. P. K. Chan · N. Razali., "Smoothing effects on the IMR and ITR," Numerical Algorithms 65(3): 401-420. 2014. DOI: $10.1007 / \mathrm{s} 11075-013-9779-7$

[12] Razali, N. \& Chan, R. P. K., "Implementation of symmetrizers in ordinary differential equations," ANZIAM Journal 55: 541, 2015. DOI: 10.21914/anziamj.v55i0.7833

[13] Rabiei, F. \& Ismail, F., "Fifth-order improved Runge-Kutta method with reduced number of function evaluations," Australian Journal of Basic and Applied Sciences 6(3): 97$105,2012$.

[14] Agnes Serawa Anak Jutang et al., "Draining Water Tank using Runge-Kutta Methods," International Journal of Recent Technology and Engineering, 8(5): 2342-2348, 2020.

[15] Rogalev, A. N. \& Rogalev, A. A., "Estimates of the accuracy of numerical solutions using regularization," Journal of Physics: Conference Series 1441(1). DOI: 10.1088/1742-6596/1441/1/012165

[16] Lewis, W. J., "The efficiency of numerical methods for the analysis of prestressed nets and pin-jointed frame structures," Computers and Structures 33(3): 791-800, 1989. DOI: 10.1016/0045-7949(89)90254-X

[17] Al-Mutib, A. N., "Stability properties of numerical methods for solving delay differential equations," Journal of Computational and Applied Mathematics 10(1): 71-79, 1984. DOI: 10.1016/0377-0427(84)90071-2 